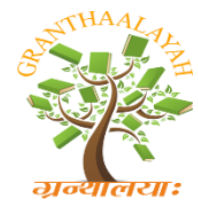
\author{
GRANTHAALAYAH \\ A knowledge Repository
}

INTERNATIONAL JOURNAL OF RESEARCH -

Science

\title{
ROLE OF SERUM IRON AND ITS ASSOCIATION WITH ANEMIC PREVALANCE AMONG PATIENTS WITH DIFFERENT TYPE OF CANCER
}

\author{
Andrew Pradeep.M ${ }^{* 1}$, Indira.G ${ }^{2}$, Sethu Nagarajan $\mathbf{R}^{3}$ \\ *1, 2, 3 Post Graduate Department of Immunology \& Microbiology, The American College \\ Madurai, Tamilnadu, India
}

DOI: https://doi.org/10.29121/granthaalayah.v5.i5(SE).2017.1965

\begin{abstract}
Cancer is a group of diseases in which cells are aggressive, invasive and sometimes metastatic. Nutritional status an important factor that contributes to immune competence for which trace minerals plays a crucial role in the biochemical and physiological activity of the system. Trace element a category of minerals essential for the biological system and plays an active role in immune effector mechanism. Normal range of iron essential for body metabolism, iron deficiencies leads to anemia which might complicate the event of tumor genesis.

Study involved 50 volunteers (36 females, 14 males) of cancer patients of Mohan Nursing Home Madurai. Serum was collected in the informed consent of the patients. Serum iron level was quantified using Atomic Absorption Spectrophotometer.

Study documented percentage deviation of serum iron concentration (85\%) with severe anemic prevalence from the control individual (without cancer) and also establish an association of iron deficiency with anemic prevalence.

Study documented the existence of Iron deficiency which is the most common cause of anemia worldwide. Iron plays a role in oxygen transfer in cytochromes, protein molecules involved in the production of energy in cells and also exhibit certain properties to facilitate antitumor status. Study concludes that serum iron modulations need to be emphasized to minimize the burdenization of the host with Clinical associated complications of Iron deficiency among patients with cancer.
\end{abstract}

Keywords: Anemia; Iron; Trace Element \& Cancer.

Cite This Article: Andrew Pradeep.M, Indira.G, and Sethu Nagarajan R. (2017). "ROLE OF SERUM IRON AND ITS ASSOCIATION WITH ANEMIC PREVALANCE AMONG PATIENTS WITH DIFFERENT TYPE OF CANCER." International Journal of Research Granthaalayah, 5(5)SE, 37-41. https://doi.org/10.29121/granthaalayah.v5.i5(SE).2017.1965. 


\section{Introduction}

Cancer is a group of diseases characterized by unregulated division and spread of cells. The cancerous cells may occur in liquids, as in leukemia. Most, however, occur in solid tumors that originally appear in various tissues in various parts of the body. By their original locations they are classified into various types of cancer, such as lung, colon, breast, or prostate cancer. Localized tumors can be removed by surgery or irradiation with high survival rates. As cancer progresses, however, it metastasizes - invading the surrounding tissues, entering the blood stream, spreading and establishing colonies in distant parts of the body (1).

Iron needs to be absorbed and maintained in the body within a narrow range for optimal health. Iron absorption is regulated. Several different proteins have been identified as contributors to the process. Iron disorders are generated by both Fe deficiency and Fe overload. All organs in human body need iron. This mineral is a fundamental element of hemoglobin - part of erythrocytes that transports oxygen to into cells. It is also contained in myoglobin that supplies muscles with oxygen. Furthermore, it is fundamental for number of enzymes and the immunity system.

Iron acts as a cancer-promoting agent by two separate yet synergistic mechanisms: 1) by producing "free radicals," and 2) by feeding cancer cells. Iron increases the production of free radicals, and-in fact-the production of free radicals is largely proportionate to the level of iron. This means that the more iron there is in the body, the more free radicals will be produced and thus the greater the risk of disease, in this case, cancer. Free radicals are oxygen-containing molecules which damage (oxidize) the DNA of cells. Since DNA controls the activities of the cell, once the DNA is damaged, the cell becomes "out of control." Essentially, all cancer cells are out of control. These cancer cells then replicate and grow rapidly and eventually infiltrate and damage the body's organs. Additionally, cancer cells consume many nutrients and thereby starve the host. One of the nutrients cancer cells need most is iron. In fact, researchers now think that iron may be a "rate-limiting" nutrient for cancer cell growth. This means that the more iron that is available, the more the cancer cells will divide and flourish, and the better chance they have of killing the host. Recent research has shown that people with high levels of iron have an increased risk for cancer $(2,3)$

Anemia is common in patients with cancer, with a prevalence approaching 50\%. This figure may rise to over $90 \%$ in patients with more advanced cancer or in those treated with chemotherapy or radiation therapy. Iron deficiency causes a characteristic anemia with small pale red blood cells, deficient in oxygen-carrying hemoglobin. Iron supplementation cures this anemia, and is one of the more gratifying treatments in the medical repertoire. Iron is stored in the bone marrow, and once full, can supply enough iron for several months of dietary iron deficiency. Women store less iron than men, and lose iron monthly in menstrual blood, and are therefore much more likely to suffer iron deficiency than men. 


\section{Materials and Methods}

Study subject: 50 volunteer Cancer patients, who were undergoing treatment in Mohan Nursing Home Madurai, were subjected to the present study. The study population involves 14 males and 36 females. The samples were collected with concerned of the patient.

Blood collection: $3 \mathrm{ml}$ of whole blood was collected from the patients with a sterile syringe. The tubes devoid of anti-coagulant were involved for the separation of serum. The serum was used for quantification of Serum Iron concentration using Atomic Absorption Spectrophotometer.

\section{Statistical Analyses}

All group data are expressed as means \pm SEMs. The Cancer group was compared with the control subjects by using one way variance analysis (ANOVA). The minimal level of significance was identified at $P<0.0001$ and found to be extremely significant by tukey Kramer test multiple comparison test.

Table 1: MEAN and SEM of Iron Concentration among Various types of cancer and control subjects

\begin{tabular}{|l|l|l|l|l|}
\hline $\begin{array}{l}\text { Cancer patients } \\
\text { Male (Stomach) } \\
\mathbf{n = 7}\end{array}$ & $\begin{array}{l}\text { Cancer patients } \\
\text { Male (Oral) } \mathbf{n = 7}\end{array}$ & $\begin{array}{l}\text { Cancer patients } \\
\text { Female (Breast) } \\
\mathbf{n = 1 8}\end{array}$ & $\begin{array}{l}\text { Cancer patients } \\
\text { Female } \\
\text { (Cervical) } \mathbf{n = 1 8}\end{array}$ & $\begin{array}{l}\text { Control subjects } \\
\mathbf{n = 1 8}\end{array}$ \\
\hline $0.1971 \pm 0.0035$ & $0.38 \pm 0.0043$ & $0.5416 \pm 0.0044$ & $0.3483 \pm 0.0041$ & $1.042 \pm 0.01841$ \\
\hline
\end{tabular}

1) Mean \pm SEMs.

2) $P$ value Significant of Cancer patients and Control subjects

Control(mg/l) vs Female (breast) $\quad * * * \mathrm{P}<0.001$

Control(mg/l) vs Female(Cervix) $\quad * * * \mathrm{P}<0.001$

Control(mg/l) vs Male(stomach) $\quad * * * \mathrm{P}<0.001$

Control(mg/l) vs Male(oral) $\quad * * * \mathrm{P}<0.001$

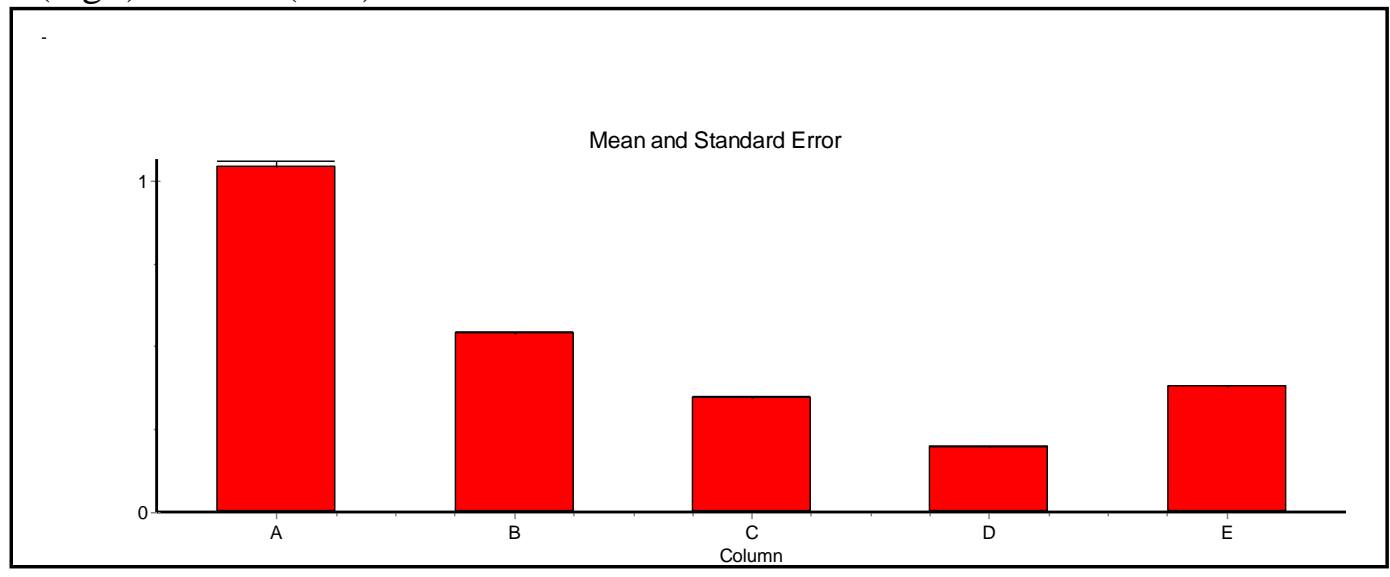

Figure 1: Represents Mean and SEM of Iron concentration among Cancer and Control Subjects 


\section{Result}

Study Documents the diminished level of Serum iron among the study population of Cancer compared with control Subjects. Study Involves Gaussian distribution and statistical analysis conforms the existence of the extreme significance of serum iron level among the study population $(\mathrm{p}<0.0001)$ one way variance analysis (ANOVA). Kolmogorov- Smirnov normality test documents that Cancer patient Male (Stomach) (0.3451), Cancer patients Male (Oral) (0.2353), Cancer patients Female (Breast) (0.2871), Cancer patients Female (Cervical) (0.2600), Control subjects (0.4278).

Iron is stored in an assimilable form predominantly in the liver and spleen. This storage form of iron is ferritin, a large molecule comprising an assembly of a variable proportion of light (L) and heavy $(\mathrm{H})$ protein subunits numbering 24 in total: each molecule of ferritin is capable of storing 4500 atoms of ferric iron. Small amounts of ferritin are found in the serum composed almost exclusively of standard and glycosylated L subunits. A large evidence base indicates that the level of serum ferritin correlates with the amount of storage iron, except in patients suffering from liver disease or inflammatory conditions (4).

Our study had 18 Breast cancer and 18 cervical cancer patients the analysis showed the decreased level of iron among them, this is because Iron imbalance is a unique physiological occurrence in women, which is likely to affect health before, during, and after the menopause. The possibility exists that iron deficiency contributes to the high recurrence of breast cancer in premenopausal women, whereas iron load might have a role in the incidence of breast cancer in postmenopausal women (5).

We also studied the iron concentrations among men with Stomach and oral cancer, they showed a diminishing level from the normal. Iron deficiency may cause oral cancer via the induction of oxidative stress. Iron deficiency produces free radicals and reactive oxygen species that potentially cause cellular injury (6). Oxidative stress is often defined as the disturbance of equilibrium of prooxidant and antioxidant systems in favor of oxidation, leading to direct damage to cellular molecules such as DNA $(7,8)$. Increased levels of oxidative stress have been associated with iron deficiency anemia in numerous studies and is thought to contribute to the pathogenesis of patients with this disorder $(9,10)$. Oxidative stress has also been linked to the development of oral cancer (11), and diets high in antioxidant/ nutrients have been associated with reduced risk for oral cancer. (12).

Anaemia may develop as a result of the malignant disease process itself; from bleeding, nutritional deficiencies, bone marrow damage, tumour infiltration of the bone marrow, or immunologic impairment of erythropoietic response. However, it probably occurs most often by iatrogenic means, as a consequence of myelosuppressive chemotherapy or radiotherapy Anaemia can result in functional deficits such as decreased exercise capacity, headaches, dyspnoea, loss of libido, and dizziness. One of the most pronounced, and most studied, clinical symptoms of anaemia is fatigue. Fatigue is the most prevalent symptom reported by patients with cancer, and has reportedly been regarded by patients as more important than nausea and vomiting (13) 


\section{Conclusion}

Iron plays a significant role and also regulates the immune functioning capacity and helps in immune surveillance against tumor. Deficiency of serum iron concentration leads to anemic associated complication and disturbs the immune surveillance mechanisms.

Both deficient and overload of serum iron concentration in the body leads to severe complications in both male and female. Men suffer due to their personal and occupational habits whereas women due to their hormonal variation. These complications promote the host to be burdenized with the impact of tumor progression and the trace element (iron) modulation needs to be emphasized to maintain a homeostatic environment.

\section{References}

[1] P. A. Dervan Jefferson, NC: McFarland, (1999).Understanding Cancer.

[2] Stevens RG, Jones DY, Micozzi MS, Taylor PR(1988). Body iron stores and the risk of cancer. N Engl J Med; 319: 1047-52

[3] Stevens RG, Graubard BI, Micozzi MS, Neriishi K, Blumberg SB(1994). Moderate elevation of body iron level and increased risk of cancer occurrence and death. Int J Cancer; 56: 364-9

[4] Lipschitz DA, Cook JD, Finch CA(1974). A clinical evaluation of serum ferritin as an index of iron stores. New Engl J Med; 290: 1213-6

[5] Xi Huang(2008). Does iron have a role in breast cancer? Lancet Oncol.; 9(8): 803-807.

[6] Halliwell B: Free radicals, antioxidants, and human disease: curiosity,cause, or consequence? Lancet 344, 721-724, 1994.

[7] Aslan M, Horoz M, Kocyigit A, Ozgonul S, Celik H, et al(2006).Lymphocyte DNA damage and oxidative stress in patients with iron deficiency anemia. Mutat Res 601, 144-149, 8.

[8] Aust AE and Eveleigh JF: Mechanisms of DNA oxidation (1999). Proc Soc ExpBiol Med 222, 246-252

[9] Vives Corrons JL, Miguel-Garcia A, Pujades MA, Miguel-Sosa A, Cambiazzo S, et al(1995). Increased susceptibility of microcytic red blood cells to in vitro oxidative stress. Eur J Haematol 55, 327-331.

[10] Kumerova A, Lece A, Skesters A, Silova A, and Petuhovs V(1998). Anaemia and antioxidant defence of the red blood cells. Mater Med Pol 30, 12-15.

[11] Huang Z, Komninou D, Kleinman W, Pinto JT, Gilhooly EM, et al(2007). Enhanced levels of glutathione and protein glutathiolation in rat tongue epithelium during 4-NQO-induced carcinogenesis. Int J Cancer 120, 1396-1401.

[12] John P. Richie, Wayne Kleinman, Patricia Marina, Patricia Abraham, and Ernst L.Wynder, Joshua E. Muscat (2008). Blood Iron, Glutathione, and Micronutrient Levels and the Risk of Oral Cancer. Nutrition and Cancer, 60(4), 474-482.

[13] GD Demetri (2001), Anaemia and its functional consequences in cancer patients: current challenges in management and prospects for improving therapy, British Journal of Cancer 84 (Supplement 1), 31-37. 